\section{A IMPLEMENTAÇÃO DAS LEIS \\ No 10.639/2003 E No 11.645/2008 E \\ O IMPACTO NA FORMAÇÁO DE PROFESSORES}

A Implementação das Leis № 10.639/2003 e № $11.645 / 2008$ e o Impacto na Formação de Professores
Wilma de Nazaré Baía Coelho ${ }^{1}$
Nicelma Josenila Brito Soares

\section{Resumo}

Este trabalho tece uma reflexão inicial acerca dos processos de formação de professores, mediante análise dos marcos legislativos que normatizam os processos educacionais em âmbito nacional. Nosso percurso contemplará em que medida a formação de professores, preconizada na legislaçáo que rege a educação brasileira, tem se aproximado das formulaçóes tecidas na produção acadêmica deste campo. Esse investimento requererá inicialmente que discorramos sobre os marcos regulatórios que estruturam o campo educacional, por meio das Leis de Diretrizes e Bases da Educação Brasileira vigente na atualidade, mediante enfoque das alteraçóes definidas

1 Doutora em Educação pela Universidade Federal do Rio Grande do Norte (UFRN). Professora da Universidade Federal do Pará (UFPA), atua no Programa de Pós-Graduação em Educação (PPGED), Programa de PósGraduação em Currículo e Gestão da Escola Básica (PPEB) e no Programa em Educação em Ciências e Matemáticas (PPGECM) da referida Universidade. Coordena o Núcleo de Estudos e Pesquisas sobre Formação de Professores e Relaçóes Étnico-Raciais (NEAB GERA/UFPA). Coordenadora do Curso de Especialização em Relaçóes Étnico-Raciais para o Ensino Fundamental, do GT 21 da ANPED $(2015$ - 2017) e da Linha Currículo e Escola Básica, do Programa de Pós-Graduação em Currículo e Gestão da Escola Básica (PPEB). Membro da Comissão Técnica Nacional de Diversidade para Assuntos Relacionados à Educaçáo dos Afro-Brasileiros (CADARA).

2 Doutoranda em Educação pelo Programa de Pós-Graduação em Educação da UFPA. Mestra em Educação pelo mesmo Programa (2010). Possui Graduação em Pedagogia pela mesma Universidade (2000). Pesquisadora do Núcleo de Estudos e Pesquisas sobre Formação de Professores e Relaçóes Étnico-Raciais (NEAB GERA/UFPA).
Educ. Foco,

Juiz de Fora, v.21, n.3, p. 573-606, 573 set. / dez. 2016 
em função da promulgação da Lei $\mathrm{n}^{\circ}$ 10.639/2003 e da Lei no 11.645/2008. Nesta empreitada, delimitaremos aspectos que configuram tal legislação para, em seguida, situarmos as produçóes acadêmicas que engendraram a adoção desta política, a fim de analisarmos os impactos da formação nas açôes de implementação das referidas leis.

Palavras-chave: Formação docente. Processos educacionais. Política educacional.

\section{IMPLEMENTATION OF LAW NO. 10,639/2003 AND NO. 11,645/2008 AND ITS IMPACT ON TEACHER EDUCATION}

\section{Abstract}

This study comes up with an initial reflection on the processes of teacher education through an analysis of legislative milestones that regulate the educational processes at a national level. Our route will include the extent to which teacher training, set out in the legislation that rules the education in Brazil, has approached the formulations elaborated into the academic production on this field. This investment will initially require that we reason about the regulatory milestones that shape the educational field, through the Laws of Guidelines and Bases of Brazilian Education [Leis de Diretrizes e Bases da Educaçâo Brasileira] in force nowadays, by focusing the modifications defined as a result of the enactment of Law no. 10,639/2003 and Law no. 11,645/2008. In this endeavor, we will outline aspects that shape such legislation, to then situate the academic productions that gave rise to the adoption of this policy and, subsequently, analyze the impact of the teacher education in the actions of implementation of the mentioned laws.

Keywords: Teacher education. Educational processes. Educational policy. 


\section{A IMPLEMENTAÇÃO DAS LEIS No 10.639/2003 E No 11.645/2008 E O IMPACTO NA FORMAÇÃO DE PROFESSORES}

Uma análise das implicações presentes entre as discussões sobre formação de professores e a adoção de políticas voltadas para esse campo indica uma dinâmica a ser verificada: a relação entre a intensificação da produção acadêmica que se ocupa com essa questão e as políticas educacionais voltadas para os processos formativos. Para análise de tal dinâmica, direcionaremos nossas contribuiçóes para os marcos legislativos que normatizam os processos educacionais em âmbito nacional, com o intuito de verificar em que medida a formação de professores, preconizada na legislação que rege a educaçáo brasileira, tem se aproximado das formulações tecidas na produção acadêmica deste campo.

Esse investimento requererá inicialmente que discorramos sobre os marcos regulatórios que estruturam o campo educacional, por meio das Leis de Diretrizes e Bases da Educação Brasileira (LDB) vigente na atualidade, mediante enfoque das alterações definidas em função da promulgaçáo da Lei no 10.639/2003 e da Lei no 11.645/2008. Nesta empreitada, delimitaremos aspectos que configuram tal legislação, para, em seguida, situarmos as produçóes acadêmicas que engendraram a adoção desta política, para analisarmos os impactos da formação nas açốes de implementação das referidas leis.

\section{OS MARCOS LEGISLATIVOS DEFINIDOS PELA LEI No 10.639/2003 E LEI No 11.645/2011}

Dentre as legislaçóes que estruturam o campo educacional, por meio da LDB (Lei no 9.394), sancionada em 20 de dezembro de 1996, iremos nos deter nas alteraçóes por meio da inserção do artigo 26-A: a obrigatoriedade de inclusão, no currículo oficial da Rede de Ensino, da temática "História e Cultura Afro-Brasileira e Indígena”. Isso pois constitui um dos
A Implementação das Leis № 10.639/2003 e № $11.645 / 2008$ e o Impacto na Formação de Professores
Educ. Foco, Juiz de Fora, $575^{\text {v. } 21, \text { n.3, p. } 573-606}$ 575 set. / dez. 2016 
indicativos a partir dos quais as demandas sociais repercutem nos processos legislativos em nossa sociedade.

A primeira, advinda das demandas do Movimento $\mathrm{Negro}^{3}$, é a institucionalização da obrigatoriedade do enfoque à temática e constitui uma realidade "diagnosticada nos estudos e pesquisas sobre o tema e denunciada, há décadas, pelas entidades do Movimento Negro" (SILVA JUNIOR, 2002, p. 12) e que necessitam de "intervenção conscienciosa" (COELHO, 2009, p. 232) com vistas a assegurar a efetividade da promoçáo do princípio constitucional da igualdade (BRASIL, 1988).

Tendo um caráter inicial de coibir manifestaçóes comportamentais de preconceito (GUIMARÃES, 2004), a legislação brasileira transitou entre a proibição de práticas preconceituosas comportamentais ou verbais contra o racismo no período de 1989 a $1997^{4}$. A criminalização da prática do racismo, instituída no art. $5^{\circ}$ da Constituição Federal de 1988, representou um avanço na legislação referente a tais práticas porque possibilitou uma superação do caráter de contravenção imputado às manifestaçôes de preconceito, ao preconizar que "XLI - a lei punirá qualquer discriminação atentatória aos direitos e liberdades fundamentais; XLI I - a prática do racismo constitui crime inafiançável e imprescritível, sujeito à pena de reclusão" (BRASIL, 1988, n.p.).

Com a participação na III Conferência Mundial Contra o Racismo, Discriminação Racial, Xenofobia e Intolerância

3 Cf. GONÇALVES, L. A. O.; SILVA, P. B. G. Movimento negro e educaçáo. Revista Brasileira de Educaçáo. Sáo Paulo, v. 15, n. 15, 2000, p. 134158; SANTOS, S. A. A Lei no $10.639 / 03$ como fruto da luta anti-racista do movimento negro. In: Educaçáo anti-racista: caminhos abertos pela Lei Federal no 10.639/03. Brasília: MEC; Secretaria de Educação Continuada, Alfabetização e Diversidade, 2005, p. 21-37; GOMES, N. L.; SILVA, P. B. G. (org.). Experiências étnico-culturais para a formaçáo de professores. Belo Horizonte: Autêntica, 2011.

4 Constituem instrumentos jurídicos voltados para tais proibiçôes: Lei no 7.716, de 5 de janeiro de 1989; Lei $\mathrm{n}^{\circ}$ 8.081, de 21 de setembro de 1990; Lei $\mathrm{n}^{\circ}$ 9.459, de 13 de maio de 1997. Cf. GUIMARÁES, 2004. 
Correlata, realizada na África do Sul, o Brasil assume o compromisso de implementar o Programa de Ação da Declaração de Durban, que previa "promoção do ensino, com o intuito de fomentar o ensino, capacitação e atividades educacionais relacionadas aos direitos humanos e à luta contra o racismo, discriminaçáo racial, xenofobia e intolerância correlata" (SILVA JUNIOR, 2002, p. 9). Tal participação representa outro avanço significativo na assunção do combate a tais práticas, por meio de ação educativa promovida pelo Estado dentro do espaço das escolas.

Devemos ressaltar, nesse contexto, que a experiência brasileira apresenta uma contribuição "singular" (COELHO; COELHO, 2013) da sociedade civil organizada, no que tange ao advento da Lei no 10.639/2003:

Ela não emergiu do interior do sistema educacional, entendido aqui como as instâncias normativas e operacionais (o Ministério e as Secretarias de Educação - estaduais e municipais) e suas instâncias constituintes e legitimadoras, como o discurso acadêmico e os cursos de formação docente. Ela nasceu da demanda da sociedade civil organizada. Foram os movimentos civis que apontaram uma lacuna na formação oferecida: o sub-dimensionamento da participaçáo do negro na formação da nacionalidade brasileira e uma orientação exclusivamente europeia na compreensão dos processos que conformavam a trajetória histórica brasileira (COELHO; COELHO, 2013, p. 95).

Esse envolvimento da sociedade civil organizada, indicando demandas que lhe são atinentes, pode ser respaldado pelas incursóes efetivadas para análise da evolução das assimetrias apresentadas na sociedade brasileira, no que concerne aos quesitos cor e raça. Para mapeamento dessa evolução, foram adotados como parâmetros os "indicadores sociais presentes nas bases de dados que contenham informaçôes estatísticas
A Implementação das Leis № 10.639/2003 e № $11.645 / 2008$ e o Impacto na Formação de Professores
Educ. Foco, Juiz de Fora, $577^{\text {v.21, n.3, p. 573-606 }}$ 577 set. / dez. 2016 
sobre a população residente no país" (PAIXÃO et al., 2010, p. 15). Tais dados informam que, a despeito dos avanços promovidos pelos marcos legislativos que incorporaram as demandas da sociedade civil organizada, uma persistência nos índices desfavoráveis para alguns segmentos populacionais ainda se atrela à experiência de alguns, dependendo de seu pertencimento racial:

O racismo, tal como operante na sociedade brasileira, baseado no critério das aparências físicas, tanto nasce no cotidiano das relaçôes assimétricas de poder, na formação de mecanismos de prestígio social, no acesso às oportunidades de mobilidade social ascendente e de direitos sociais, como também verte das estruturas sociais localizadas no plano do aparelho do Estado (racismo institucional), das empresas do setor privado, das escolas, dos meios de comunicação, que legitimam as desvantagens estruturais que terão de ser vividas pelos que portam fenótipos diferentes do grupo hegemônico (PAIXÃO et al., 2010, p. 22).

Nesse cenário, a promulgação em 2003 da Lei no 10.639 - que institui a obrigatoriedade da inclusão de "História e Cultura Afro-brasileira" nos currículos escolares da rede pública e privada de Ensino Fundamental - constitui um dos encaminhamentos para atender àquela demanda histórica do Movimento Negro, contribuindo para colocar oficialmente discursos e vozes historicamente silenciados nos currículos das nossas escolas.

No que tange à Lei $\mathrm{n}^{\circ} 11.645$, sancionada em março de 20085, Silva (2012) salienta uma dinâmica que a aproxima da experiência mencionada em relaçáo à lei promulgada em 2003: a visibilidade conferida às demandas dos povos indígenas, ocorrida em função de sua mobilizaçáo política, concorreu

5 Disponível em: <http://www.planalto.gov.br/ccivil_03/_Ato2007-2010/2008/ Lei/11645.htm>. Acesso em: 20 maio 2015. 
para as conquistas de direitos fixados na Constituição Federal de 1988 e para que "a sociedade em geral (re)descobrisse os índios" (SILVA, 2012, p. 3).

Esse movimento apresenta-se circundado por uma legislação que contempla as diversidades dos povos indígenas ${ }^{6}$ no que se refere à educação: um dos marcos, o Referencial Curricular Nacional para as Escolas Indígenas, "estabelece enfaticamente a diferenciação da escola indígena das demais escolas do sistema pelo respeito à diversidade cultural e à língua materna, e pela interculturalidade" (BRASIL, 1998a, p. 5). Já a Resoluçáo 3, de 10 de novembro de 1999, fixa as Diretrizes Nacionais para o funcionamento das escolas indígenas e dá outras providências; o Referencial para a Formação de Professores Indígenas (BRASIL, 2002a) contempla processos de formação, atendendo às especificidades dos povos indígenas; os Parâmetros Curriculares em Ação: Educação Escolar Indígena apresentam como seu escopo "ser realizado em um contexto de formação de profissionais da educação, propiciando o estabelecimento de vínculos com as práticas locais" (BRASIL, 2002b, p. 13).

Tais aspectos conformam uma dinâmica na qual as mobilizaçóes dos povos indígenas, apontadas por Silva (2012) como elementos desencadeadores da atençáo a seus direitos, demarcam a implantação da educação indígena, com peculiaridades que contemplem esses povos, bem como assinalam uma possibilidade de subversão no tocante às representaçóes instauradas em relação a esses povos na sociedade brasileira.

Com as inserçóes oficiais nos currículos, no que diz respeito à cultura e à história afro-brasileira e indígena,

6 "Compreende pessoas etnicamente diferenciadas, que se consideram descendentes dos povos que habitavam a Amazônia, antes da chegada do invasor europeu, as quais possuem direitos, assegurados constitucionalmente, que conservam usos, costumes e tradiçôes característicos da cultura originária em sua forma de organização cultural e social" (COELHO; SANTOS; SILVA, 2015, p. 27).
A Implementação das Leis № 10.639/2003 e № $11.645 / 2008$ e o Impacto na Formação de Professores
Educ. Foco, Juiz de Fora, 579 v. 21 , n.3, p. 573-606 579 set. / dez. 2016 
vislumbra-se uma estratégia de alteração nas formulaçôes veiculadas na escola, uma vez que sua efetivaçáo concorre para encaminhar "a formulaçáo de outra trama do processo de formação da nacionalidade, por meio da qual todos os agentes possam identificar-se e orientar-se". (COELHO; COELHO, 2013, p. 96).

Essa "outra trama" anunciada por Coelho e Coelho (2013) materializa a referência à diversidade e ao reconhecimento de identidades pessoais, os quais constituem uma diretriz para a Educação Nacional: nessa direção, atentarmos para o objetivo de "contribuir para a constituição de identidades afirmativas, persistentes e capazes de protagonizar ações autônomas e solidárias em relação a conhecimentos e valores indispensáveis à vida cidadâ" voltada para a superação de discriminações e exclusóes em múltiplos contextos e no interior das escolas, devidas ao racismo, ao sexismo e a preconceitos originados pelas situaçóes socioeconômicas, regionais, culturais e étnicas.

A percepção da relevância da escola nesse processo como "uma instância privilegiada de reflexão e problematização" (BRASIL, 1998b, p. 103) remete à necessidade de resgate da autoestima no que se refere ao imaginário negativo e discriminatório construído em relação a alguns dos agentes que protagonizaram os processos de formação da nacionalidade, apontada por Coelho e Coelho (2013). Assim, essa efetivaçáo se conforma mediante a ação do educador e educadora ao compreender o contexto do racismo e como esse fenômeno interfere nessa autoestima, e que sua não subversão "impede a construção de uma escola democrática”, conforme adiantado por Nilma Lino Gomes (2003, p. 77).

A assunção desse empreendimento, aos processos de formaçáo de professores, representa um investimento responsável pela pavimentação de outro trajeto para a

7 Resolução CEB no 2 / 1998, art. 3º, III. 
compreensão de tais processos formativos em nível macro da sociedade brasileira.

Nesse empreendimento, várias iniciativas legais são adotadas com vistas a institucionalizar a implementação de uma educação que atente para a diversidade que pauta as relaçóes étnico-raciais em nossa sociedade, seja por meio de orientação quanto aos conteúdos a serem inseridos e trabalhados ou às alteraçóes curriculares a serem adotadas (BRASIL, 2004a), seja por meio do detalhamento dos papéis a serem institucionalmente assumidos (BRASIL, 2004b) ou de documento pedagógico para "orientar e balizar os sistemas de ensino e as instituiçóes correlatas na implementação das Leis $\left[\mathrm{n}^{\circ}\right]$ 10.639/2003 e [no] 11.645/2008" (BRASIL, 2012, p. 16).

Essa demanda explicitada nos marcos legais que fomentam essa alteração de compreensóes e de posturas tem se constituído objeto de investigaçóes, as quais se ocupam de revisitar práticas, diagnosticar dificuldades e propor avanços. Nesse aspecto, convém situarmos como as produçóes acadêmicas representam contributo para essa revisão.

\section{A QUESTÁO ÉTNICO-RACIAL ENGENDRANDO PRODUÇÓES ACADÊMICAS}

As produçôes acadêmicas que engendraram a adoção de políticas de combate à discriminação na sociedade brasileira têm sido assumidas, no âmbito de alguns processos de pesquisa, como uma conjugação de "um projeto acadêmico e um projeto social - o fim das desigualdades" (COELHO, 2014, p. 81, grifos da autora).

Tal ambição já se esboçava minimamente em documentos oficiais anteriores a 2003: a proposta de que questôes sociais (como as questóes referentes ao preconceito e à discriminaçáo) fossem tratadas metodologicamente pela transversalidade constituiu, antes da promulgação da Lei $n^{\circ}$ $10.639 / 2003$ e da Lei $n^{\circ} 11.645 / 2008$, o expediente adotado para o encaminhamento das questóes étnico-raciais no interior
A Implementação das Leis № 10.639/2003 e № $11.645 / 2008$ e o Impacto na Formação de Professores
Educ. Foco, Juiz de Fora, 581 v. 21, n.3, p. 573-606 1 set. / dez. 2016 
da escola. A despeito das lacunas na definição e na criação de metodologias para o combate à discriminação (SOUZA, 2001), os Parâmetros Curriculares oferecem contribuição para o combate às práticas dessa natureza, representando um avanço na abordagem desse tema na escola.

As discussôes acerca das relaçóes raciais espraiam-se para a dimensão educacional a partir da década de 80 , mencionada como um marco, em nosso país, na discussão das relaçôes raciais em sua interface com a educação ${ }^{8}$. Essa demarcação decorre da edição no 63 dos Cadernos de Pesquisa, da Fundaçáo Carlos Chagas, em 1987 (SOUZA, 2001), em que artigos oriundos dos debates promovidos durante o Seminário "O Negro e a Educação" tornaram-se referência para os trabalhos que os sucederiam.

A profusão de estudos que se debruçaram sobre a temática educação e relaçóes raciais contemplou as formulaçóes do pensamento racial brasileiro em suas diferentes vertentes, seja na desconstrução do mito da democracia racial, seja na denúncia da conservação da ideologia da superioridade do branco em nosso país, materializando-se no campo da educação por meio do vínculo entre conhecimento, identidade e poder (SANTOS, 2007). Ainda corroboram as discussóes acerca das desigualdades raciais (HASENBALG; SILVA, 1992), ao evidenciar que a assimetria das relaçôes raciais ${ }^{9}$ brasileiras penaliza os negros na escola "seja por inferiorizá-los enquanto grupos, por desvalorizar a sua cultura ${ }^{10}$ ou por mantê-los

8 Gomes (2011a) indica que a redemocratização do país e a consolidação dos cursos de Pós-Graduação concorrem para a inserçáo de intelectuais negros nas universidades públicas, e uma consequente produção no campo das relaçôes étnico-raciais.

9 Curvier teria sido, assim, conforme Schwarcz (1993), o primeiro a utilizar a nomenclatura raça com o sentido que hoje usamos. O conceito de raça, conforme Guimarães (2002), é uma categoria socialmente constituída.

10 Compartilhamos da compreensão de cultura negra como "particularidade cultural construída historicamente por um grupo étnico/racial específico, não de maneira isolada, mas no contato com outros grupos e povos" (GOMES, 2003, p. 77). 
nos estatutos inferiores da hierarquia social" (RIBEIRO, 2005, p. 9).

No desencadear desse processo, um levantamento de pesquisas apresentadas no GT $21^{11}$, da Associação Nacional de Pós-Graduação (ANPED), voltadas para a dimensão educacional de acordo com o recorte racial, evidenciou em sua abordagem que, a partir da segunda metade da década de 80, quatro grandes campos de pesquisa delineavam-se no estudo da educação e relaçôes raciais: o dos "Diagnósticos", o dos "Materiais Didáticos", o da "Formação de Identidades" e o dos "Estereótipos" (SISS; OLIVEIRA, 2007).

Nesses campos de pesquisa, as análises dos diagnósticos da situaçáo educacional dos negros no Brasil traziam à baila os "acidentes de percurso" que marcavam a trajetória das crianças negras na escola. Esses estudos possibilitavam a percepçáo de que o acesso de crianças brancas e negras ao sistema de ensino era diferenciado, com prejuízo considerável para este último grupo: desde o que tange às escolas para as quais eram destinados - geralmente públicas e de periferia - até as atividades educativas executadas por professores não qualificados, os quais as desenvolviam sob o suporte de recursos didáticos "deficientes ou de baixa qualidade" (SISS; OLIVEIRA, 2007, p. 5).

Para além das diferentes perspectivas e contextos nos quais ocorriam, os estudos que enfocavam as desigualdades educacionais entre os grupos raciais no Brasil geralmente apontavam as práticas racistas inseridas no ambiente escolar, presentes em falas, comportamentos e conteúdos didáticopedagógicos empregados por professores e por outros agentes institucionais, bem como enunciam o potencial da escola como instrumento gerador de uma nova conscientização quanto às diferenças raciais (BRANDÃO, 2006).

11 O GT 21 é o Grupo de Trabalho que agrega, no presente momento, produçóes vinculadas ao tema das relaçóes étnico-raciais e educação.
A Implementação das Leis № 10.639/2003 e № $11.645 / 2008$ e o Impacto na Formação de Professores 
Nessa direção, alguns projetos inscritos no Concurso Negro e Educação (PINTO; SILVA, 2000) ${ }^{12}$, sob chancela da ANPED e da Ação Educativa, com o apoio da Fundação Ford, focalizavam as relaçóes que ocorriam no espaço escolar envolvendo alunos, professores e funcionários, bem como processos de ensino-aprendizagem, conteúdos, percepçóes, representaçóes e açôes dos partícipes do cotidiano da escola.

Os estudos voltados para a interface racismo e educação na sociedade brasileira apontam, há muito tempo, para a necessidade de reflexão quanto ao lugar que os debates sobre as questóes raciais ocupavam na escola. A falta dessa reflexão apresenta-se, dentre outros fatores, como responsável por uma prática de segregação no espaço escolar que apresentará vários efeitos para os grupos que são alvo deste processo (COELHO, 2009).

Os estudos iniciados na década de $80^{13}$ contemplando o ambiente escolar e suas configuraçôes, no que tange à perpetuação de desigualdades, anunciavam um panorama que ainda se encontra em processo de enfrentamento.

Levantamentos recentes apontam para uma ampliaçáo nas produçóes em volta da temática racial, com quantitativos orbitando aproximadamente 75,86\%, dentre teses e dissertaçóes produzidas a partir de 2000 , nas quais, dentre os aspectos verificados, ainda se evidencia a crítica aos elementos sob os quais a escola apresenta-se estruturada: "a) seletiva; b)

12 Pinto; Silva (2000) analisaram 135 projetos submetidos à seleçấo para o Concurso Negro e Educação. Nesta análise, as autoras agruparam os projetos por temas correlatos, a partir da temática principal, classificando-os nos seguintes assuntos: o sistema educacional e as questóes étnico-raciais; livros didáticos: análises e propostas; propostas curriculares; políticas/iniciativas com vistas à melhoria da situaçáo educacional do negro; expectativas e aspiraçôes dos alunos; a situaçáo educacional do negro; formaçáo de professores; aprendizagem/aproveitamento escolar; contribuiçáo do negro para o processo educativo e questóes de gênero entre os negros.

13 Gomes (2011) indica que a redemocratização do país e a consolidação dos cursos de Pós-Graduação concorrem para a inserçáo de intelectuais negros nas universidades públicas e uma consequente produção no campo das relaçôes étnico-raciais. 
hierárquica; c) fundada nos pressupostos do universalismo e da igualdade abstrata; d) individualista" (REGIS, 2009, p. 197).

Para além das denúncias, um aspecto a ser registrado no tocante às produçôes sobre as relaçôes raciais na experiência brasileira incide na transição de uma posição de meros objetos de investigação para a posição de sujeitos produtores do conhecimento. Dois eventos significativos, responsáveis pela ampliação e disseminação da produção acadêmica brasileira, subsidiam este argumento: o primeiro, por meio das atividades dos Grupos de Trabalhos (GTs) efetivados nas reunióes anuais da ANPED, especificamente no GT 21, "integrado por pesquisadores e pesquisadoras negros e não-negros, cuja produção científica está localizada na área das Relações Étnico/Raciais e Educação" (ANPED, s.d., n.p.), o qual, em levantamento recente efetivado por ocasião dos 10 anos do referido GT (VALENTIN; PINHO; GOMES, 2012), dá conta desse protagonismo assumido por esses intelectuais e dessa ampliação da temática durante a existência desse GT.

O segundo evento a ser destacado consiste nos Congressos Brasileiros de Pesquisadores(as) Negros(as) (COPENE), vinculados à Associação Brasileira de Pesquisadores(as) Negros(as) (ABPN), criada em 2000 a partir do I Congresso Brasileiro de Pesquisadores(as) Negros(as), sediado na Universidade Federal de Pernambuco (UFPE). Os COPENEs sinalizam um movimento de ampliação dos debates, os quais, desde a versão coordenada pela Prof. ${ }^{a}$ Dr. ${ }^{a}$ Lídia Cunha e pelo Prof. Dr. Henrique Cunha Júnior até a última, (ocorrida em 2014 na Universidade Federal do Pará), sob coordenação da Prof. ${ }^{a}$ Dr. ${ }^{a}$ Wilma de Nazaré Baía Coelho, vêm efetuando um balanço positivo no que tange à produção de pesquisadores(as) negros(as) e não negros(as) sobre a temática em diversos campos do conhecimento - Quadro 1.
A Implementação das Leis № 10.639/2003 e № $11.645 / 2008$ e o Impacto na Formação de Professores
Educ. Foco, Juiz de Fora, 585 set. / dez. 2016 


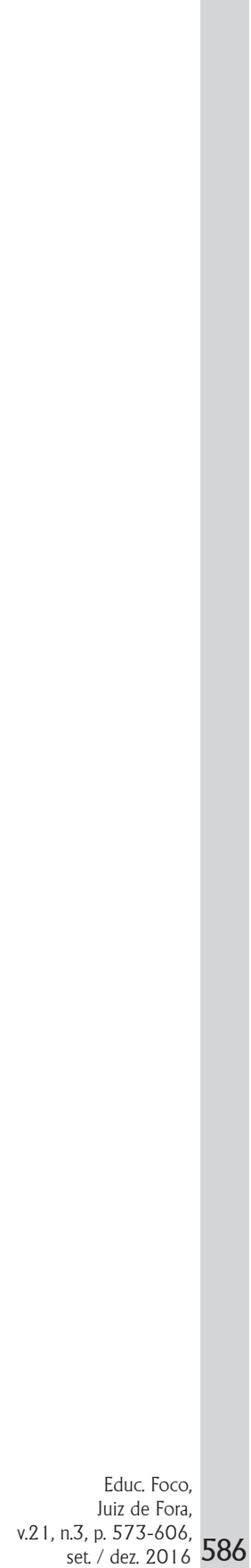

Quadro 1 - Congressos Brasileiros de Pesquisadores(as) Negros(as) (COPENES) - 2000/2014.

\begin{tabular}{|c|c|}
\hline Versáo & I COPENE \\
\hline Períod. & 22 a 25 de novembro de 2000 \\
\hline Munic./Uf & Recife/PE \\
\hline Públ. & Aprox. 320 \\
\hline $\begin{array}{l}\text { Aspectos } \\
\text { Registrados }\end{array}$ & $\begin{array}{l}\text { Crescimento numérico; qualidade da produção. } \\
\text { Persistência de barreiras e ausência dos meios materiais } \\
\text { de suporte ao desenvolvimento de pesquisas pretendidas } \\
\text { pelos(as) pesquisadores(as) negros(as). } \\
\text { Grande concentraçáo de pesquisadores(as) se deu nas } \\
\text { seguintes áreas de conhecimento: educação, saúde, história, } \\
\text { sociologia e antropologia. }\end{array}$ \\
\hline Versáo & II COPENE \\
\hline Períod. & 25 a 29 de agosto de 2002 \\
\hline Munic./Uf & São Carlos/SP \\
\hline Públ. & Aprox. 450 \\
\hline $\begin{array}{l}\text { Aspectos } \\
\text { Registrados }\end{array}$ & $\begin{array}{l}\text { Aprovou a constituição da Associação Brasileira de } \\
\text { Pesquisadores(as) Negros(as) (não restringindo a } \\
\text { participaçáo de pesquisadores não negros). } \\
\text { Transparecem na produção os efeitos das mudanças sociais } \\
\text { ocorridas na década de } 90 .\end{array}$ \\
\hline Versáo & III COPENE \\
\hline Períod. & 06 a 10 de setembro de 2004 \\
\hline Munic./Uf & São Luís/MA \\
\hline Públ. & Aprox. 1.000 \\
\hline $\begin{array}{l}\text { Aspectos } \\
\text { Registrados }\end{array}$ & Apoio SEPPIR, SECADI e Fundação Cultural Palmares. \\
\hline Versáo & IV COPENE \\
\hline Períod. & 13 a 16 de setembro de 2006 \\
\hline Munic./Uf & Salvador/BA \\
\hline Públ. & Mais de 1.200 \\
\hline $\begin{array}{l}\text { Aspectos } \\
\text { Registrados }\end{array}$ & $\begin{array}{l}\text { Participação de docentes e discentes, pesquisadores(as) } \\
\text { de várias universidades brasileiras, bem como mestres } \\
\text { populares, detentores de conhecimento, mas não } \\
\text { necessariamente portadores de títulos acadêmicos - } \\
\text { interessados pela temática das relaçóes étnico-raciais. }\end{array}$ \\
\hline
\end{tabular}




\begin{tabular}{|c|c|}
\hline Versáo & V COPENE \\
\hline Períod. & 29 de julho a 01 de agosto de 2008 \\
\hline Munic./Uf & Goiânia/GO \\
\hline Públ. & Aprox. 1.300 \\
\hline $\begin{array}{l}\text { Aspectos } \\
\text { Registrados }\end{array}$ & $\begin{array}{l}\text { Atendeu à necessidade de contínua reflexão acerca da } \\
\text { produçáo de intelectuais negros(as), em grande parte } \\
\text { "invisíveis" na ciência brasileira e nas sociedades científicas, } \\
\text { ainda que tenhamos indivíduos de renome internacional. }\end{array}$ \\
\hline Versáo & VI COPENE \\
\hline Períod. & 26 a 29 de julho de 2010 \\
\hline Munic./Uf & Rio de Janeiro/RJ \\
\hline Públ. & Aprox. 2.000 \\
\hline $\begin{array}{l}\text { Aspectos } \\
\text { Registrados }\end{array}$ & $\begin{array}{l}\text { Apresentou e discutiu os processos de produção/difusão de } \\
\text { conhecimentos intrinsecamente ligados às lutas históricas } \\
\text { empreendidas pelas populaçôes negras. } \\
\text { Possibilitou um crescimento quantitativo e qualitativo da } \\
\text { produção científica de pesquisadores(as) negros(as) e sobre } \\
\text { populaçóes negras, especialmente no Brasil. }\end{array}$ \\
\hline Versáo & VII COPENE \\
\hline Períod. & 16 a 20 de julho de 2012 \\
\hline Munic./Uf & Florianópolis/SC \\
\hline Públ. & Aprox. 1.000 \\
\hline $\begin{array}{l}\text { Aspectos } \\
\text { Registrados }\end{array}$ & $\begin{array}{l}\text { Incorporou três eventos concomitantes, a saber: o II } \\
\text { Seminário Internacional de Pesquisadores(as) Negros(as); o } \\
\text { I Seminário de Iniciação Científica da ABPN; o I Encontro } \\
\text { Nacional de Pesquisadoras e Pesquisadores em Saúde da } \\
\text { População Negra. } \\
\text { Oportunizou a diferentes pesquisadores(as) a construção de } \\
\text { um balanço da produção acadêmica até aqui e definiu os } \\
\text { desafios para os próximos anos. }\end{array}$ \\
\hline
\end{tabular}




\begin{tabular}{|c|c|}
\hline Versáo & VIII COPENE \\
\hline Períod. & 29 de julho a 02 de agosto de 2014 \\
\hline Munic./Uf & Belém/PA \\
\hline Públ. & Mais de $1.500^{14}$ \\
\hline $\begin{array}{l}\text { Aspectos } \\
\text { Registrados }\end{array}$ & $\begin{array}{l}\text { Ampliou os eventos efetivados concomitantemente: III } \\
\text { Seminário Internacional de Pesquisadores Negros; II } \\
\text { Seminário de Iniciação Científica da ABPN; Simpósio } \\
\text { da American Educational Research Association (AERA); } \\
\text { VI Seminário Nacional; VIII Seminário Regional sobre } \\
\text { Formaçáo de Professores e Relaçóes Étnico-Raciais. } \\
\text { Tornaram-se inéditos alguns produtos até esta versão: } \\
\text { vídeo-documentário em memória dos(as) pesquisadores(as) } \\
\text { e lideranças falecidos(as); vídeo-homenagem à condecorada } \\
\text { desta ediçâo do evento; produção de } 1.200 \text { exemplares dos } \\
\text { Anais do VIII Congresso Brasileiro de Pesquisadores(as) } \\
\text { Negros(as); produção de 1.200 exemplares do Relatório } \\
\text { de Atividades de Preparação do VIII Congresso Brasileiro } \\
\text { de Pesquisadores(as) Negros(as); produção de } 1.200 \\
\text { exemplares da Programação do VIII Congresso Brasileiro de } \\
\text { Pesquisadores(as) Negros(as); produçáo de } 1.200 \text { exemplares } \\
\text { do CD-ROM dos Anais do VIII Congresso Brasileiro de } \\
\text { Pesquisadores(as) Negros(as); entrega em outubro de } 2014 \\
\text { do relatório final à presidência da ABPN; publicação online } \\
\text { dos trabalhos completos, apresentados no evento. }{ }^{15}\end{array}$ \\
\hline
\end{tabular}

Fonte: Adaptado de ABPN (s.d., n.p.). Disponível em: <http://www.abpn.org.br/ novo/index.php/eventos/copenes $>$. Legenda: Períod. $=$ Período. Públic. $=$ Público.1415

Os dois eventos constituem dois outros indicativos da ampliação das discussóes no tocante à temática e podem ser compreendidos como estratégias favorecedoras de novas formulaçôes e compreensões, de revisões de práticas e de ruptura com a dinâmica que se instaura na sociedade brasileira. Tal alteração não pode ser desencadeada por meio de "meia dúzia de frases politicamente corretas" (COELHO, 2007, p. 13, grifos da autora). A ruptura com essa dinâmica

14 Para dados mais específicos referentes à oitava versão do COPENE, o relatório entregue à Presidência da Associaçáo Brasileira de Pesquisadores(as) Negros(as) constitui a base para apresentaçáo dos aspectos náo localizados no site da ABPN (COELHO; SOARES, 2014a).

15 Idem 
envidaria uma "intervenção conscienciosa" (COELHO, 2009, p. 232) mediante uma abordagem sistemática da questáo racial nos processos de formação - com vistas ao oferecimento de um suporte teórico que subsidiaria práticas docentes que têm se apresentado sob bases do "improviso" (COELHO; COELHO, 2008) e "próximas ao senso comum" (COELHO, 2009, p. 218).

Para subsidiar essa argumentação, afluirmos a experiência dos docentes que já se encontram inseridos na escola, analisando como a sua formaçáo continuada de professores contribui para ilustrar o percurso a ser traçado para o alcance do "projeto acadêmico" e do "projeto social" (COELHO, 2014, p. 81) sobre o qual têm se debruçado as investigaçóes produzidas dentro desta temática nos últimos anos.

Em face da presença de duas categorias relevantes neste artigo (formação de professores e formação continuada), convém ressaltar que partilhamos da compreensão de Gatti e Barretto (2009): “a necessidade de adoção de uma estratégia de ação articulada entre as diferentes instâncias que formam professores e as que os admitem como docentes" (GATTI; BARRETTO, 2009, p. 255). Essa articulação também é indicada em síntese integrativa sobre as produçôes acadêmicas dedicadas à análise da formação de professores, na qual a "necessidade de integração entre o Estado, as agências formadoras e as agências contratantes de profissionais de educação" (ANDRÉ, 1999, p. 305) figura como um dos eixos mais focalizados nos trabalhos que investigavam a formação inicial.

A compreensão dessa necessidade subsidia a percepção do potencial que a parceria entre a universidade e a escola básica apresenta, como processo estratégico, para reversão de representaçóes e formulaçôes instauradas no imaginário coletivo no tocante a alguns grupos que participaram e participam da organização de nossa sociedade.
A Implementação das Leis № 10.639/2003 e № $11.645 / 2008$ e o Impacto na Formação de Professores
Educ. Foco, Juiz de Fora,

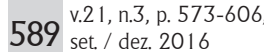




\section{AS AÇÓES PARA IMPLEMENTAÇÁO DA LEI No 10.639/2003 E LEI No 11.645/2008 E A FORMAÇÁO CONTINUADA DE PROFESSORES}

Pesquisas que apresentam a dinâmica das escolas têm indicado possibilidades - em que pese às limitaçôes verificadas - de que nesse espaço sejam vivenciadas práticas voltadas para a subversão da realidade que marca a experiência dos segmentos excluídos e invisibilizados na sociedade brasileira.

Esse aspecto é constatado por meio de pesquisa em escolas da Região Norte, na qual o enfoque à temática racial foi localizado em 3 das 6 escolas investigadas, indicando, no tocante aos locais que desenvolvem trabalhos que contemplam a questão étnico-racial, que tais atividades se apresentam como estratégias "muito eficazes para a reversão da autoestima dos estudantes negros e pardos [bem como o estabelecimento de] relaçóes entre o procedimento adotado e a competência desenvolvida junto aos estudantes" (COELHO; COELHO, 2014, p. 26).

Para exemplificação a partir de uma das áreas especiais mencionadas na legislaçáo em tela, verifica-se que a ideia do ensino de História como mobilizador da consciência histórica e, consequentemente, um favorecedor do exercício da cidadania que pauta uma expectativa de melhorias para o futuro da sociedade (VALÉRIO; RIBEIRO, 2013). Tal expectativa justifica-se pela possibilidade de instauração de uma nova compreensão, inclusive em termos de participação na formaçáo da sociedade brasileira e, por conseguinte, de uma nova percepção de nacionalidade que inclua todos os segmentos cujas histórias na constituição de nossa sociedade têm sido silenciadas.

Essa nova percepção apresenta desdobramentos na revisão da história do negro no Brasil, "em diversos estudos e por diferentes intelectuais e ativistas negros" (MÜLLER; SANTOS, 2014, p. 88) e representa um movimento que tem impulsionado a mobilização dos sujeitos que, ao longo 
dos tempos, foram "excluídos da história [com vistas a restituição de] sua condição de agentes históricos” (RIBEIRO, 2007, p. 45).

Esse movimento tem na escola e no ensino de História uma estratégia acionadora, em face do que expóem Coelho; Coelho (2013):

Em relação aos professores de História, os quais nos interessam particularmente, a nova legislação demanda não apenas o domínio dos saberes historiográficos relativos à África e à Cultura Afro-Brasileira. Ela requer, fundamentalmente, o acionamento de competências que viabilizem o enfrentamento do preconceito e de seus desdobramentos nocivos na formação de crianças e adolescentes, por meio da construção de uma nova forma de se pensar a formação da nação e da nacionalidade (COELHO; COELHO, 2013, p. 97).

As competências a serem acionadas para gerar a subversão dos processos invisibilizatórios que se imprimiram às populaçóes negra e indígena enfrentam entraves que transitam por toda a ordem de fatores, um dos quais, no que tange à prática dos professores de História e à cultura e história afrobrasileira, dá conta de que o "saber histórico escolar relacionado à África e à Cultura Afro-Brasileira necessita amadurecimento" (COELHO; COELHO, 2013, p. 106).

Alia-se a esse contexto o fato de que ainda que as pesquisas localizem, no âmbito das escolas, algumas iniciativas para o trato da questáo étnico-racial, tal enfoque ainda se apresenta pautado no "voluntarismo docente", na ausência de conhecimento formal da lei, na vinculação a um teor ético e moral e no fato de que tal enfoque na escola advém de iniciativas pontuais (COELHO; COELHO, 2014).

Esse panorama vai concorrer para a situação que se instaura no âmbito educacional brasileiro, na qual a descontinuidade dos projetos gestados na escola matiza o panorama da
A Implementação das Leis № 10.639/2003 e № $11.645 / 2008$ e o Impacto na Formação de Professores
Educ. Foco, Juiz de Fora, 591 v.21, n.3, p. 573-606 
"implementação das diretrizes curriculares nacionais para a educação das relaçóes étnico-raciais” (BRASIL, 2008, p. 13).

Uma reversão desse cenário pode ser registrada, mediante a adoção de estratégias que conformem novas representaçôes, a partir de um trabalho a ser desenvolvido na escola. Nesse aspecto, a formação continuada de professores assume relevância em conjunto com outras estratégias a serem adotadas.

A efetividade de investimentos para fomento a iniciativas dessa natureza, presentes em balanço elaborado em 2008, identificam algumas açôes do Ministério da Educação com vistas a assegurar a implementação da Lei no 10.639/2003, conforme expomos no Quadro 2 a seguir:

Quadro 2 - Estratégias de divulgação e distribuição de material pedagógico sobre a Lei no 10.639/2003.

Reuniões dos Fóruns de Educação e Diversidade Étnico-Racial

\begin{tabular}{|c|c|}
\hline Açóes & $\begin{array}{l}\text { Reuniôes dos Fóruns de Educação e Diversidade } \\
\text { Étnico-Racial }\end{array}$ \\
\hline Ano de Origem & 2004,2006 e 2008 \\
\hline $\begin{array}{l}\text { Resultados } \\
\text { Alcançados }\end{array}$ & $\begin{array}{l}\text { Participação de representantes de } 21 \text { UF e articulação } \\
\text { de SMEDs, SEEs e Movimentos Sociais. Rearticulação } \\
\text { para constituição dos Fóruns Estaduais. }\end{array}$ \\
\hline Açóes & Diálogos Regionais (5 Regiōes, 27 UF) \\
\hline Ano de Origem & 2008 \\
\hline $\begin{array}{l}\text { Resultados } \\
\text { Alcançados }\end{array}$ & $\begin{array}{l}\text { Consulta pública sobre o Plano Nacional de } \\
\text { Implementação da Lei no } 10.639 / 2003 \text {. } \\
\text { Transparecem na produçáo os efeitos das mudanças } \\
\text { sociais ocorridas na década de } 90 \text {. }\end{array}$ \\
\hline Açóes & $\begin{array}{l}\text { Publicação de } 23 \text { títulos sobre a temática da Educação } \\
\text { das Relaçóes Étnico-Raciais. } \\
\text { Títulos com tiragem acima de } 50.000 \text { exemplares: } \\
\text { "Superando o racismo na escola" (2005); "Educação } \\
\text { anti-racista: caminhos abertos pela lei 10.639/2003" } \\
\text { (2005) e Orientaçóes e açôes para a Educação das } \\
\text { Relaçôes Étnico-Raciais (2006). }\end{array}$ \\
\hline Ano de Origem & 2004-2008 \\
\hline $\begin{array}{l}\text { Resultados } \\
\text { Alcançados }\end{array}$ & 223.900 de exemplares distribuídos. \\
\hline
\end{tabular}




\begin{tabular}{|l|l|}
\hline \multirow{3}{*}{ Açóes } & $\begin{array}{l}\text { Publicação das Diretrizes Curriculares Nacionais para a } \\
\text { Educaçáo das Relaçóes Étnico-Raciais e para o Ensino } \\
\text { de História e Cultura Afro-Brasileira e Africana (Parecer } \\
\text { CNE/CP3/2004, Resolução CNE no 1/2004 e Lei no } \\
10.639 / 2003) .\end{array}$ \\
\hline Ano de Origem & 2005 \\
\hline $\begin{array}{l}\text { Resultados } \\
\text { Alcançados }\end{array}$ & 1.000 .000 de exemplares distribuídos. \\
\hline
\end{tabular}

Tais dados podem exemplificar os investimentos acionados para arcar com o que Padinha denomina de "o custo do racismo" (PADINHA, 2014, p. 97). Nesse aspecto, com direcionamento de açôes para os processos formativos com vistas a reversão do panorama instaurado na sociedade brasileira no tocante às questôes raciais.

Além das açôes e investimentos elencados no balanço do Ministério da Educação, ressaltamos a ampliação das estratégias contemplando a formaçáo continuada de professores, por meio de programas distintos, conforme indicamos no Quadro 3.

Quadro 3 - Oferta de formação continuada de professores pelos programas do MEC/SECAD.

\begin{tabular}{|c|c|c|c|c|}
\hline $\begin{array}{l}\text { Projetos/ } \\
\text { Programas }\end{array}$ & Período & $\begin{array}{c}\text { Carga } \\
\text { horária }\end{array}$ & $\begin{array}{l}\text { Metas de } \\
\text { formaçáo }\end{array}$ & $\begin{array}{l}\text { Resultados } \\
\text { alcançados }\end{array}$ \\
\hline Uniafro & $\begin{array}{l}2005- \\
2006\end{array}$ & $\begin{array}{c}\text { Oferta } \\
\text { diferenciada }\end{array}$ & $\begin{array}{c}10.647 \\
\text { professores }\end{array}$ & $\begin{array}{l}\text { Dados não } \\
\text { disponíveis }\end{array}$ \\
\hline Uniafro $^{(1)}$ & $\begin{array}{c}2008- \\
2010\end{array}$ & $\begin{array}{l}\text { De } 80 \text { a } 120 \\
\text { horas, em } 3 \\
\text { modalidades }\end{array}$ & $\begin{array}{c}\text { No de professores } \\
\text { em: } \\
\text { Especialização: } \\
1.245 . \\
\text { Aperfeiçoamento: } \\
1.470 . \\
\text { Extensão: } 3.480 .\end{array}$ & $\begin{array}{c}\text { Em } \\
\text { início de } \\
\text { execução }\end{array}$ \\
\hline
\end{tabular}




\begin{tabular}{|c|c|c|c|c|}
\hline $\begin{array}{l}\text { Projetos/ } \\
\text { Programas }\end{array}$ & Período & $\begin{array}{c}\text { Carga } \\
\text { horária }\end{array}$ & $\begin{array}{l}\text { Metas de } \\
\text { formaçáo }\end{array}$ & $\begin{array}{l}\text { Resultados } \\
\text { alcançados }\end{array}$ \\
\hline $\begin{array}{l}\text { Educação- } \\
\text { Africanidades- } \\
\text { Brasil }\end{array}$ & 2006 & 120 horas & $\begin{array}{l}26.054 \text { inscritos, } \\
27 \text { UF, } \\
704 \text { municípios, } \\
4.000 \text { escolas. }\end{array}$ & $\begin{array}{l}6.800 \\
\text { professores } \\
\text { da rede } \\
\text { pública } \\
\text { concluíram } \\
\text { o curso. }\end{array}$ \\
\hline $\begin{array}{l}\text { Oficina } \\
\text { cartográfica } \\
\text { sobre } \\
\text { Geografia } \\
\text { Afro-Brasileira } \\
\text { e Africana }\end{array}$ & 2005 & $\begin{array}{c}\text { Oficinas } \\
\text { (sem dados } \\
\text { de carga } \\
\text { horária) }\end{array}$ & $\begin{array}{c}4.000 \\
\text { educadores, } \\
\text { em } 7 \text { UF }\end{array}$ & $\begin{array}{l}\text { Dados não } \\
\text { disponíveis }\end{array}$ \\
\hline $\begin{array}{l}\text { Projeto } \\
\text { Educadores } \\
\text { pela } \\
\text { Diversidade }\end{array}$ & $\begin{array}{l}2004- \\
2005\end{array}$ & 40 horas & $\begin{array}{l}\text { Dados não } \\
\text { disponíveis }\end{array}$ & $\begin{array}{c}3.121 \\
\text { formandos }\end{array}$ \\
\hline $\begin{array}{l}\text { Curso } \\
\text { Educaçáo } \\
\text { e Relaçóes } \\
\text { Étnico-Raciais }\end{array}$ & 2005 & 120 horas & $\begin{array}{l}\text { Dados não } \\
\text { disponíveis }\end{array}$ & $\begin{array}{c}240 \\
\text { formandos }\end{array}$ \\
\hline $\begin{array}{l}\text { Programa } \\
\text { A Cor da } \\
\text { Cultura }^{(2)}- \\
\text { Tiragem } 2000\end{array}$ & $\begin{array}{l}2004- \\
2006\end{array}$ & $\begin{array}{l}\text { Dados não } \\
\text { disponíveis }\end{array}$ & $\begin{array}{l}4.000 \\
\text { educadores, } \\
\text { em } 7 \text { UF }\end{array}$ & $\begin{array}{c}3.000 \\
\text { professores } \\
\text { capacitados }\end{array}$ \\
\hline
\end{tabular}

Fonte: Balanço da ação do MEC para a implementação da Lei nº 10.639/03 (MEC/ SECAD, 2008).

Legenda: (1) = MEC/SECAD. Seleção de Projetos 2008.

(2) = Programa desenvolvido em parceria com a Fundação Roberto Marinho/Canal Futura.

Dentre os recursos advindos desses programas, o Núcleo de Estudos e Pesquisas sobre Formação de Professores e Relaçôes Étnico-Raciais (NEAB GERA/UFPA) foi contemplado com o edital do UNIAFRO, em 2010, para promover um curso de Especialização em Relaçóes Étnico-Raciais para o Ensino Fundamental. A proposta de formação consistiu em "facultar a professores normalmente infensos às oportunidades de formação continuada a competência necessária para o trato com as questôes étnico-raciais" (COELHO, 2014, p. 74). 
Subsidiado pelos resultados das pesquisas no ambiente escolar, o NEAB GERA/UFPA, por meio da formação em tela, "pretendeu contribuir para a formação dos docentes em termos de formaçáo continuada, visando à modificação de sua concepçáo e prática no tocante à educação para as relaçôes étnico-raciais" (COELHO, 2014, p. 75). Nesse sentido, a proposta de formação foi concluída por meio da apresentação de um Projeto de Intervenção Educacional, no qual os alunos-professores articularam os aspectos teóricos discutidos nas disciplinas cursadas com a matéria ou o serviço ao qual estavam inseridos nas escolas nas quais mantinham vinculação, para implementação da Lei no 10.639/2003.

Assim, a partir dessa proposta, foram formuladas estratégias didáticas que se constituíram a partir da "intervenção conscienciosa" (COELHO, 2009, p. 232), a qual podemos apresentá-la como sendo a

resultante de uma reflexão prévia, de uma compreensão profunda sobre a temática e do domínio das competências necessárias à transformação daquela compreensão em sequencias didáticas que garantissem a transposição do saber acadêmico, adquirido no curso de Especialização em tela, em saber escolar (COELHO, 2014, p. 75).

Essa pretensão envidou a elaboração de 26 Projetos de Intervenção Educacional, responsáveis pela ampliação do enfoque à temática racial em várias escolas da rede pública de Ensino Fundamental no estado do Pará, conforme arrolamos no Quadro 4:
A Implementação das Leis № 10.639/2003 e № $11.645 / 2008$ e o Impacto na Formação de Professores
Educ. Foco,

Juiz de Fora, v.21, n.3, p. 573-606 595 set. / dez. 2016 
Quadro 4 - Projetos de Intervenção Educacional advindos do curso de Especialização em Relaçôes Étnico-Raciais, promovido pelo NEAB GERA/UFPA, em 2010.

\begin{tabular}{|c|c|}
\hline ORD. & PROPOSTA \\
\hline 1 & $\begin{array}{l}\text { O corpo marcado em movimento: práticas corporais dialogando } \\
\text { com as relaçóes raciais. }\end{array}$ \\
\hline 2 & $\begin{array}{l}\text { Relaçóes étnico-raciais: um “olhar” sobre identidade cultural dos } \\
\text { alunos da } 4^{\text {a }} \text { série. }\end{array}$ \\
\hline 3 & $\begin{array}{l}\text { Valorização da identidade negra na escola do Ensino } \\
\text { Fundamental. }\end{array}$ \\
\hline 4 & $\begin{array}{l}\text { Valorização da identidade afro-brasileira com alunos do } 4^{\circ} \text { ano do } \\
\text { Ensino Fundamental. }\end{array}$ \\
\hline 5 & $\begin{array}{l}\text { Importância do samba para a identidade dos atores que compóem } \\
\text { o processo de ensino-aprendizagem: uma proposta de intervenção } \\
\text { na Escola Estadual de Ensino Fundamental e Médio "Vera } \\
\text { Simplício". }\end{array}$ \\
\hline 6 & $\begin{array}{l}\text { Relações raciais para o Ensino Fundamental: o trato pedagógico } \\
\text { da identidade negra. }\end{array}$ \\
\hline 7 & $\begin{array}{l}\operatorname{Re}(f a z e n d o) \text { o saber: açóes para a inserçáo da temática étnico- } \\
\text { racial no currículo escolar na E. E. E. F. M. Esmerina Bou-Habib. }\end{array}$ \\
\hline 8 & $\begin{array}{l}\text { O apelido enquanto identidade pejorativa a partir do âmbito } \\
\text { escolar. }\end{array}$ \\
\hline 9 & $\begin{array}{l}\text { Escola Santa Sofia: espaço da inclusão racial negra - Barcarena - } \\
\text { Pará. }\end{array}$ \\
\hline 10 & $\begin{array}{l}\text { Leituras, narrativas e contos africanos no Ensino Fundamental: } \\
\text { práticas de respeito e valorizaçáo da cultura africana. }\end{array}$ \\
\hline 11 & $\begin{array}{l}\text { As interfaces entre educação e representaçóes: identidade e estética } \\
\text { do negro no cotidiano escolar. }\end{array}$ \\
\hline 12 & $\begin{array}{l}\text { Histórias do quilombo: resgatar e (re)contar para construir } \\
\text { identidades negras. }\end{array}$ \\
\hline 13 & Afrodescendentes em imagens e palavras. \\
\hline 14 & A educação como ferramenta de transformação. \\
\hline 15 & $\begin{array}{l}\text { Práticas de leitura: uma experiência de valorização das relaçóes } \\
\text { raciais na escola. }\end{array}$ \\
\hline 16 & $\begin{array}{l}\text { Um retrato sem moldura: reconhecendo e valorizando a } \\
\text { identidade negra na escola. }\end{array}$ \\
\hline 17 & $\begin{array}{l}\text { Focus de diferentes olhares: o uso de vídeo e a produção de } \\
\text { fotografias como ferramentas para o reconhecimento e respeito às } \\
\text { diferenças étnico-raciais. }\end{array}$ \\
\hline
\end{tabular}




\begin{tabular}{|c|c|}
\hline ORD. & PROPOSTA \\
\hline 18 & $\begin{array}{l}\text { Uma proposta como trabalhar a cultura e os valores dos africanos } \\
\text { e afrodescendentes nas aulas de Língua Portuguesa da Educaçáo } \\
\text { de Jovens e Adultos (EJA). }\end{array}$ \\
\hline 19 & $\begin{array}{l}\text { Quem sou eu? Contribuindo para a construção da identidade } \\
\text { negra na escola. }\end{array}$ \\
\hline 20 & Discutindo a identidade racial da criança na escola. \\
\hline 21 & $\begin{array}{l}\text { Africanicidades: o estudo da participação africana na formação } \\
\text { cultural brasileira. }\end{array}$ \\
\hline 22 & Educaçáo para a diversidade, respeitando a riqueza das diferenças. \\
\hline 23 & $\begin{array}{l}\text { O uso das novas tecnologias para o ensino das relaçôes Étnico- } \\
\text { Raciais no Ensino Fundamental e a Lei } 10.639 / 2003 \text {. }\end{array}$ \\
\hline 24 & $\begin{array}{l}\text { Relaçôes raciais e Educação Básica: proposta pedagógica para a } \\
\text { implementação da Lei no } 10.639 / 2003 \text {. }\end{array}$ \\
\hline 25 & $\begin{array}{l}\text { Açóes afirmativas na sala de aula: a literatura infantil com temas } \\
\text { raciais como instrumento de positivação da identidade negra. }\end{array}$ \\
\hline 26 & Os tambores negros do carimbó na sala de aula. \\
\hline
\end{tabular}

A Implementação das Leis № 10.639/2003 e № $11.645 / 2008$ e o Impacto na Formação de Professores

Fonte: Arquivos da coordenação do curso de Especialização em Relações ÉtnicoRaciais para o Ensino Fundamental (NEAB GERA/UFPA, 2010).

Essa experiência e esses produtos corroboram com a percepção acerca dos impactos da formação continuada de professores como sendo uma das açóes para o enfrentamento das desigualdades por meio do trato da questáo étnico-racial no cotidiano das escolas.

Em face do que expomos, a proposta foi replicada em 2012, na formação continuada promovida na Escola de Apicação da UFPA, com intervenção do NEAB GERA/ UFPA. Sobrevieram, então, novas propostas a partir de discussóes promovidas nessa ocasião - as quais transcrevemos no Quadro 5.

Educ. Foco, Juiz de Fora, 
Quadro 5 - Projetos de Intervenção Educacional advindos da formação continuada na Escola de Aplicação da UFPA, promovida pelo NEAB GERA/UFPA, em 2012.

\begin{tabular}{|l|l|l|}
\hline ORD. & \multicolumn{1}{|c|}{ PROPOSTA } & \multicolumn{1}{c|}{ DISCIPLINA(S) } \\
\hline $\mathbf{0 1}$ & $\begin{array}{l}\text { Identidades: Quem sou eu? } \\
\text { Quem somos nós? } \\
\text { Diferenças: Nós somos assim! }\end{array}$ & $\begin{array}{l}\text { Educação Infantil e Ensino } \\
\text { Fundamental (séries iniciais). }\end{array}$ \\
\hline $\mathbf{0 2}$ & Quem sou eu? & Educação Geral e Artes. \\
\hline $\mathbf{0 3}$ & $\begin{array}{l}\text { Tem grupo africano na formação } \\
\text { do Grão-Pará: os bantos. }\end{array}$ & $\begin{array}{l}\text { Ensino Fundamental (séries } \\
\text { finais). }\end{array}$ \\
\hline $\mathbf{0 4}$ & Áfricas. & $\begin{array}{l}\text { Ensino Fundamental (séries } \\
\text { finais). }\end{array}$ \\
\hline $\mathbf{0 5}$ & $\begin{array}{l}\text { Cartografia cultural afro- } \\
\text { brasileira: uma experiência } \\
\text { Médisciplinar no Ensino }\end{array}$ & $\begin{array}{l}\text { Geografia, Literatura, Língua } \\
\text { Portuguesa, Física, Química, } \\
\text { Biologia História (Ensino } \\
\text { Médio). }\end{array}$ \\
\hline $\mathbf{0 6}$ & $\begin{array}{l}\text { As Áfricas Atlânticas do século } \\
\text { XIV ao século XVIII. }\end{array}$ & Ensino Médio. \\
\hline
\end{tabular}

Fonte: Arquivos do Núcleo GERA - Relatório da Formaçấo Continuada na Escola de Aplicação da UFPA. "A Lei no 10.639/2003 em perspectiva na Educação Básica” (2012).

Se as pesquisas conduzidas por Coelho dão conta de que "África e Cultura Afro-brasileira permanecem como fatores externos ao currículo" (COELHO; COELHO, 2014, p. 35), as experiências indicando os produtos da intervençáo mencionada por Coelho (2009) (cuja importância é propositalmente reiterada no decorrer desse texto) apresentam aspectos a considerar no que tange às açóes efetivadas na escola, com vistas a assegurar a efetividade da promoção do princípio constitucional da igualdade (BRASIL, 1988).

\section{ALGUMAS CONSIDERAÇÓES}

Os dados das pesquisas indicam que o encaminhamento desta questão apresentam limitaçôes que precisam ser enfrentadas, ainda que já se constatem nas escolas. As propostas de enfrentamento, mediante a formação continuada de professores, acenam como uma das possibilidades para 
que o equacionamento das desigualdades vigentes em nossa sociedade constitua como objeto de superação.

As experiências obtidas por meio da formaçáo continuada enquanto uma das açóes propulsoras na implementação da Lei $n^{\circ} 10.639 / 2003$ corroboram com as constataçóes de Müller e Coelho (2014) acerca da "associação quase direta entre os desafios de implementaçáo da Lei no $10.639 / 2003$ e os procedimentos referentes à formaçáo de professores [aliada a um] consenso de ações" (MÜLLER; COELHO, 2004, p. 54).

Nesse panorama, o estabelecimento de parceria entre escola e universidade se apresenta como uma estratégia viabilizadora de subversão das realidades detectadas nas produçôes acadêmicas, instaurando novos cenários, sejam nas escolas, sejam na Academia. Nas primeiras, consolidam-se práticas em curso ou instauram-se aquelas em que a lei ainda não é implementada ou sequer se constitua como objeto de conhecimento dos agentes que nelas se inserem. Na segunda, fomentam-se novas produçóes que anunciem estratégias de reversão ao panorama instaurado na sociedade brasileira, cumprindo o "projeto acadêmico" e o "projeto social" (COELHO, 2014, p. 81) - gestados no cerne de grupos de pesquisa que têm atentado para a necessidade de subversão do cenário brasileiro.

Os avanços decorrentes das ações de implementação da Lei ${ }^{\circ} 10.639 / 2003$ a partir da formação continuada se evidenciam mediante reconhecimento de instituiçóes fomentadoras de práticas voltadas para o trato com a questáo da diversidade em nossa sociedade. ${ }^{16}$

16 O Centro de Estudos das Relaçóes de Trabalho e Desigualdades (CEERT) promove anualmente o Prêmio Educar para a Igualdade Racial, evidenciando práticas escolares que tratem a temática racial. Dentre os premiados na $6^{\text {a }}$ edição do certame, situa-se uma egressa do curso de Especialização em Ralaçóes Étnico-Raciais para o Ensino Fundamental, promovido pelo NEAB GERA/UFPA. Disponível em: <http://www.ceert.org.br/acontece/noticia. php?id=2981 >. Acesso em: 20 maio 2015. Outro projeto, advindo de açóes de formaçáo continuada, foi premiado pelo Fundo Baobá para Equidade Racial. Disponível em: <http://www.portal.ufpa.br/imprensa/noticia. php?cod=9881>. Acesso em: 20 maio 2015.
A Implementação das Leis № $10.639 / 2003$ e № $11.645 / 2008$ e o Impacto na Formação de Professores
Educ. Foco, Juiz de Fora, 599 v. 21, n.3, p. $573-606$ 
Para além do reconhecimento, o desdobramento das açóes efetivadas na escola, na autoestima de estudantes negros e negras tem sido um elemento de constatação das pesquisas.

Precisamos situar, nesses avanços, os desafios que ainda se apresentam em superar o caráter de iniciativas pontuais e individuais dos professores na implementação das leis, adotando tal enfrentamento do ponto de vista institucional, mediante compromisso a ser estabelecido entre todos os agentes que integram a escola e inserção no Projeto Pedagógico.

Ainda se almeja um trabalho por meio de um enfrentamento pedagógico "enraizado" - tanto na Formação Inicial quanto na continuada - nas instituiçóes formadoras como nas escolas, porém de modo estrutural, no sentido de Nilma Lino Gomes (2012), isto é,

à capacidade de o trabalho desenvolvido na escola na perspectiva da Lei $n^{\circ} 10.639 / 03$ e das suas Diretrizes Curriculares Nacionais se tornar parte do cotidiano escolar, ou seja, da organização, da estrutura, do Projeto PolíticoPedagógico, dos projetos interdisciplinares, da formaçáo continuada e em serviço dos profissionais, independentemente da atuaçáo específica de um(a) professor(a) ou de algum membro da gestão e coordenação pedagógica (GOMES, 2012, p. 27).

Os distanciamentos, recorrentemente alertados pela autora, para a efetivação "enraizada" dessas práticas na escola requerem divisão de responsabilidades para sua efetivação entre todos os agentes envolvidos no processo. Outra dimensáo a ser considerada, não menos relevante, é o parco diálogo entre escola e universidade, que também constitui um dos muitos desafios a permearem as limitaçôes de uma formação continuada desprovida de elementos balizadores - tanto do ponto de vista teórico quanto do ponto de vista prático - de uma nova compreensão no tocante às questóes raciais, tal como vem conformando, há muito tempo, a realidade brasileira. 


\section{REFERÊNCIAS}

ANDRÉ, M. et al. Estado da Arte da Formação de Professores no Brasil. Educação \& Sociedade, ano XX, n. 68, p. 301-309, dezembro 1999.

ABPN - Associação Brasileira de Pesquisadores(as) Negros(as). Copenes. Florianópolis, s.d. Disponível em: <http://www.abpn. org.br/novo/index.php/eventos/copenes>.

ANPED - Associação Nacional de Pós-Graduação e Pesquisa em Educação. Breve histórico do Grupo de Trabalho (GT) 21 Educaçáo e Relaçóes Étnico-Raciais. Rio de Janeiro, s.d. Disponível em: <http://www.anped.org.br/grupos-de-trabalho/ gt 21 -educa $\%$ C3\%A7\%C3\%A3o-e-rela\%C3\%A7\%C3\%B5es\%C3\%A9tnico-raciais>. Acesso em: 20 maio 2015.

BRANDÁO, A. Teses e dissertaçóes sobre desigualdades educacionais e açáo afirmativa. Rio de Janeiro: Laboratório de Políticas Públicas, 2006.

BRASIL. Constituição da República Federativa do Brasil. Brasília: Senado, 1988.

BRASIL. Lei $\mathrm{n}^{\circ} \mathbf{1 0 . 6 3 9}$ de 9 de janeiro de 2003. Altera a Lei no 9.394/1996, que estabelece as diretrizes e bases da educação nacional, para incluir no currículo oficial da Rede de Ensino a obrigatoriedade da temática "História e Cultura Afro-brasileira", e dá outras providências. Diário Oficial da República Federativa do Brasil. Brasília, 9 jan. 2003.

BRASIL. Contribuiçóes para implementaçáo da Lei no 10.639/2003. Brasília: MEC/UNESCO, 2008.

BRASIL. Conselho Nacional de Educação (CNE). Parecer do Conselho Nacional de Educaçáo - Câmara Plena (CNE/CP) $n^{\circ}$ 3, de 10 de março de 2004. Institui as Diretrizes Curriculares Nacionais para a Educação das Relaçôes Étnico-Raciais e para o Ensino de História e Cultura Afro-Brasileira e Africana. Brasília: MEC, 2004a. Disponível em: <http://portal.mec.gov.br/cne/ arquivos/pdf/003.pdf>. Acesso em: 20 maio 2015. 
BRASIL. Ministério da Educação. Resolução CNE/CP n 01, de 17 de junho de 2004. Brasília: MEC, 2004b. Disponível em: <http:// portal.mec.gov.br/cne/arquivos/pdf/res012004.pdf>. Acesso em: 20 maio 2015.

Plano nacional de implementaçáo das diretrizes curriculares nacionais para educação das relaçóes étnicoraciais e para o ensino de História e Cultura Afro-brasileira e Africana. Brasília: MEC, 2012. Disponível em: <http://portal.mec.gov.br/ index.php?option $=$ com_docman \&view $=$ download $\&$ alias $=10098$ diretrizes-curriculares\&Itemid=30192>. Acesso em: 20 maio 2015.

Ministério da Educação e do Desporto. Secretaria de Educação Fundamental. Referencial curricular nacional para as escolas indígenas. Brasília: MEC/SEF, 1998a.

. Parâmetros curriculares nacionais: terceiro e quarto ciclos do ensino fundamental: introdução aos parâmetros curriculares nacionais. Brasília: MEC/SEF, 1998b.

Referenciais para a formaçáo de professores indígenas. Brasília: MEC/SEF, 2002a.

. Caderno de apresentaçáo: programa parâmetros em ação de educação escolar indígena. Luís Donisete Benzi Grupioni (org.). Brasília: MEC/SEF, 2002b.

COELHO, W. de N. B. Silêncio e cor: relaçóes raciais e a formação de professoras no estado do Pará (1970-1989). In: Reuniáo anual da ANPED, 30. Anais... Caxambu-MG, 2007.

A cor ausente: um estudo sobre a presença do negro na formação de professores. 2. ed. Belo Horizonte: Mazza, 2009.

. O Núcleo GERA e a experiência do enfrentamento da questão étnico-racial: ensino, pesquisa e extensão (2006-2014). In: SANTANA, M.; COELHO, W. N. B.; CARDOSO, P. de J. (org.). $\mathrm{O}$ enfrentamento do racismo e preconceito no Brasil: a experiência dos NEABs. Itajaí: Casa Aberta, 2014.

COELHO, W. de N. B.; COELHO, M. C. O improviso em sala de aula: a prática docente em perspectiva. In: . (org.). Raça, cor e diferença: a escola e a diversidade. Belo Horizonte: Mazza, 2008. p. 104-123. 
COElHO, M. C.; COELHO, W. de N. B. Jogando verde e colhendo maduro: historiografia e saber histórico escolar no ensino de História da África e da cultura Afro-Brasileira. Revista Territórios \& Fronteiras, Cuiabá, v. 6, n. 3, dez. 2013, p. 92-107.

Por linhas tortas - a educação para a diversidade e a questão étnico-racial em escolas da Regiấo Norte: entre virtudes e vícios. In:

Entre virtudes e vícios: educação, sociabilidades, cor e ensino de História. São Paulo: Livraria da Física, 2014. p. 15-41 (Coleção Formaçẫo de Professores \& Relaçóes Étnico-raciais).

COELHO, W. de N. B.; SOARES, N. J. B. Relatório final do VIII Congresso Brasileiro de Pesquisadores(as) Negros(as). São Paulo: Livraria da Física, 2014.

COELHO, W. de N. B.; SANTOS, R. A. dos; SILVA, R. M. de N. B. Educação e Diversidades na Amazônia. São Paulo: Livraria da Física, 2015 (Coleção Formação de Professores \& Relações Étnico-raciais).

GATTI, B. A; BARRETTO, E. S. de S. Professores do Brasil: impasses e desafios. Brasília: UNESCO, 2009. Disponível em:<http:// unesdoc.unesco.org/images/0018/001846/184682por.pdf>.

GOMES, N. L. Cultura Negra e Educação. Revista Brasileira de Educaçáo, São Paulo, n. 23, maio/jun./jul./ago. 2003.

Diversidade étnico-racial, inclusão e equidade na educação brasileira. Revista Brasileira de Política e Administração da Educaçáo, v. 27, p. 109-121, 2011.

As práticas pedagógicas com as relaçóes étnico-raciais nas escolas públicas: desafios e perspectivas. In: (org.). Práticas pedagógicas de trabalho com relaçóes étnico-raciais na escola na perspectiva da Lei 10.639/2003. Brasília: MEC/UNESCO, 2012. p. 19-33.

GOMES, N. L.; SILVA, P. B. G. (org.). Experiências étnicoculturais para a formaçáo de professores. Belo Horizonte: Autêntica, 2011.

GONÇALVES, L. A. O.; SILVA, P. B. G. Movimento negro e educação. Revista Brasileira de Educaçáo, São Paulo, v. 15, n. 15, 2000. p. 134-158.
A Implementação das Leis № 10.639/2003 e № $11.645 / 2008$ e o Impacto na Formação de Professores
Educ. Foco, Juiz de Fora,

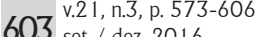
603 set. / dez. 2016 
GUIMARÁES, A. S. A. Classes, raças e democracia. São Paulo: 34, 2002.

Preconceito e discriminaçáo. Sáo Paulo: Fundação de Apoio à Universidade de São Paulo, 2004.

HASENBALG, C. A.; SILVA, N. do V. Relaçóes raciais no Brasil Contemporâneo. Rio de Janeiro: Rio Fundo, 1992.

MÜLLER, T. M. P.; SANTOS, J. L. R. dos. A presença/ausência da história e cultura negra na escola. In: MÜLLER, T. M.; COELHO, W. de N. B. Relaçóes étnico-raciais e diversidade. Niterói: UFF; Alternativa, 2014.

MÜLLER, T. M. P.; COELHO, W. de N. B. A Lei no 10.639/2003 e a formação de professores: trajetórias e perspectivas. In:

(Org.). Relaçóes étnico-raciais e diversidade. Niteroi: UFF; Alternativa, 2014.

PADINHA, M. do S. R. Relaçóes raciais: a pesquisa na PósGraduação em Educação no Brasil (2005-2010). Tese (Doutorado em Educação), Universidade Federal do Pará. Instituto de Ciência da Educação, Programa de Pós-Graduação em Educação. Belém: UFPA, 2014.

PAIXÃO, M. et al. (org). Relatório anual das desigualdades raciais no Brasil 2009-2010: Constituição cidadã, seguridade social e seus efeitos sobre as assimetrias de cor ou raça. Rio de Janeiro: Garamond, 2010.

PINTO, R. P.; SILVA, P. B. G. Negro e educação: temáticas, problemas, perspectivas de pesquisa. In: Reunião anual da ANPED, 23. Anais... São Paulo: Associação Nacional de Pós-Graduação e Pesquisa em Educação, 2000. 1 CD-ROM.

RÉGIS, K. E. Relaçóes etnicorraciais e currículos escolares em teses e dissertaçóes produzidas nos programas de pós-graduação stricto sensu em Educação - Brasil (1987-2006). Tese (Doutorado em Educação) - Pontifícia Universidade Católica de São Paulo. São Paulo: PUC, 2009.

RIBEIRO, C. M. As pesquisas sobre o negro e a educação no Brasil: uma análise de suas concepções e propostas. In: Reunião anual da ANPED, 28. Anais... Caxambu: ANPED, 2005. 
RIBEIRO, R. R. Livros didáticos de História: trajetórias em movimento. In: JESUS, N. M. de et al. Ensino de História: trajetórias em movimento. Cáceres: Unemat, 2007.

SANTOS, S. A. A Lei no 10.639/03 como fruto da luta antiracista do movimento negro. In: Educaçáo anti-racista: caminhos abertos pela Lei Federal no 10.639/03. Brasília: MEC/ Secretaria de Educação Continuada, Alfabetização e Diversidade, 2005. p. 21-37.

SANTOS, M. T.; CANEN, A. Desafiando o preconceito racial: a escola como organização multicultural. In: Reunião anual da ANPED, 30. ANPED: 30 anos de pesquisa e compromisso social. Caxambu: ANPED, 2007.

SCHWARCZ, L. M. O espetáculo das raças: cientistas, instituiçóes e questão racial no Brasil (1870-1930). São Paulo: Cia. das Letras, 1993.

SILVA JUNIOR, H. Discriminaçáo racial nas escolas: entre a lei e as práticas sociais. Brasília: UNESCO, 2002.

SILVA, E. Povos indígenas: história, culturas e o ensino a partir da lei 11.645. Revista Historien, UPE/Petrolina, v. 7, p. 39-49, 2012.

SISS, A.; OLIVEIRA, I. Trinta anos de Anped, as pesquisas sobre a educação dos afro-brasileiros e o GT 21: marcas de uma trajetória. In: Reunião anual da ANPED, 30. GT 21 - Trabalhos Encomendados. Caxambu: ANPED, 2007.

SOUZA, E. F. Repercussóes do discurso pedagógico sobre relaçôes raciais nos PCNs. In: CAVALLEIRO, E. (org.). Racismo e antiracismo na educaçáo: repensando nossa escola. São Paulo: Summus, 2001. p. 39-64.

VALÉRIO, M. E.; RIBEIRO, R. R. Para que serve a História ensinada? A guerra de narrativas, a celebração das identidades, a morte da política. Revista Territórios \& Fronteiras, Cuiabá, v. 6, n. 3, dez., 2013. p. 39-52.

VALENTIN, S.; PINHO, V.; GOMES, N. L. (org.) Relaçóes étnico-raciais, educaçáo e produçáo do conhecimento: 10 anos do GT 21 da Anped. Belo Horizonte: Nandyala, 2012.

Submetido em:10/ 09/ 2016 Aprovado em: 10/ 09/ 2016
A Implementação das Leis № 10.639/2003 e № $11.645 / 2008$ e o Impacto na Formação de Professores
Educ. Foco, Juiz de Fora, 605 v. 21, n.3, p. 573-606 set. / dez. 2016 